\title{
Editorial
}

doi: http://dx.doi.org/10.18259/iet.2016010

\section{EL APORTE DE LA INVESTIGACIÓN JURÍDICA}

Para empezar, todo estudiante de derecho o abogado debe —necesariamente - realizar actividades de investigación como complemento importante al ejercicio de la profesión o apuntando a ello. Por supuesto, nos referimos a aquellos casos en los que el profesional del derecho no haya dedicado completamente su tiempo a la actividad académica; en tal contexto, la investigación es un elemento esencial e inescindible del desarrollo académico.

La importancia de tal cometido gira en torno a dos productos esenciales: por un lado, permitirá identificar el nivel académico que ha logrado el investigador jurídico y, por tanto, su grado de responsabilidad en su formación profesional y actualización de conocimiento de las reglas, principios, doctrinas y decisiones que componen el derecho. Y, por el otro, da cuenta de una actividad de didáctica propia que le brindará elementos críticos necesarios para el análisis y uso de categorías jurídicas durante el ejercicio, dando cuenta a la comunidad de su capacidad para la adecuada utilización de herramientas jurídicas.

En este apartado no pretendemos lograr una definición de investigación jurídica o las pautas para el procedimiento que el investigador deba seguir. Nuestro objetivo es hacer visible la importancia de la investigación como instrumento para el reforzamiento del ejercicio profesional y no como actividad propia de quienes dedicaron su carrera a la academia y estudio del derecho.

El derecho es un sistema en constante mutación, la investigación es un arma para lograr un seguimiento adecuado de tal fenómeno. 